\title{
Minimizacija potrošnje pogonskih sredstava u destilacijskoj koloni s toplinskom integracijom i bez toplinske integracije za separaciju binarnog sustava aceton-metanol
}

DOI: $10.15255 / \mathrm{KUI} .2018 .009$

$\mathrm{KUI}-41 / 2018$

Prispjelo 9. travnja 2018.

Prihvaćeno 5. srpnja 2018.

\author{
N. Mustafić* i E. Karić \\ Katedra za hemijsko inženjerstvo, Tehnološki fakultet, Univerzitet u Tuzli \\ 75000 Tuzla, Bosna i Hercegovina
}

\begin{abstract}
Sažetak
U ovom radu razvijeni su matematički modeli za destilacijsku kolonu s toplinskom integracijom i bez toplinske integracije. Simulacija matematičkih modela primijenjena je za određivanje potrošnje energije u destilacijskoj koloni za razdvajanje binarnog sustava acetona i metanola. Predloženi modeli određuju vrijednosti procesnih varijabli s ciljem utvrđivanja minimalne potrošnje pogonskih sredstava. Prikazana je usporedba rezultata toplinski integrirane destilacijske kolone s rezultatima neintegrirane destilacijske kolone. Rezultati su pokazali da se ušteda energije može postići primjenom toplinske integracije. Predloženi modeli mogu se primijeniti za projektiranje novih ili preuređenje postojećih destilacijskih kolona za razdvajanje binarnih smjesa.
\end{abstract}

\section{Ključne riječi}

Binarni sustav, destilacijska kolona, toplinska integracija, pogonska sredstva, simulacija procesa destilacije

\section{Uvod}

Destilacija je jedan od najvažnijih separacijskih procesa u kemijskom inženjerstvu, u kojem se razdvajanje postiže zbog razlika u hlapljivosti komponenata, ${ }^{1}$ unatoč tome što je energetski intenzivan proces i što ima nisku termodinamičku učinkovitost (niža od $10 \%$ ). ${ }^{2}$ Procjenjuje se da destilacija čini $3 \%$ svjetske potrošnje energije i preko $50 \%$ operativnih troškova pogona, a spada u procese visokih kapitalnih investicija. ${ }^{3}$ Niska termodinamička učinkovitost $\mathrm{i}$ energetska intenzivnost dugo su vremena zanemarivane zbog niske cijene energije sve do sredine 1970-ih godina nakon prve velike svjetske energetske krize. ${ }^{2}$ Nakon toga istraživanja energetske učinkovitosti postaju aktualna i predstavljaju motivaciju za istraživanje mnogih istraživača u svijetu. S ciljem smanjenja potrošnje energije u procesima destilacije mogu se primjenjivati razne metode procesne integracije kao što su metoda pinch, koja spada u termodinamičke metode i matematičko programiranje koje se temelji na modeliranju i optimizaciji procesnih struktura. ${ }^{4}$ Spomenute metode mogu se primjenjivati kako za sintezu novih procesa ${ }^{5}$ tako i za analizu i optimalizaciju postojećih procesa. Toplinska integracija destilacijskih sustava može se postići vanjskom ili unutarnjom integracijom. Vanjskom integracijom moguće je isparivače, kondenzatore ili predgrijače toplinski integrirati s drugim procesnim tokovima koji nisu vezani uz proces destilacije. ${ }^{6}$ Unutarnja integracija uglavnom podrazumijeva upotrebu toplinskih pumpi, kao npr. rekompresija para vrha destilacijske kolone, čija se energija nakon toga upotrebljava u isparivaču. ${ }^{7}$ Jana, ${ }^{8}$ Kiss i Olujićc ${ }^{2}$ predstavili su detaljniji pregled tehnika toplinske integracije destilacijskih kolona.

Khalifa i Emtir ${ }^{9}$ razmatrali su simulaciju konvencionalnih destilacijskih konfiguracija kao i toplinski integrirane konfiguracije za separaciju ternarnih sustava. Konfiguracije su optimirane primjenjujući troškovnu funkciju cilja radi pronalaska konfiguracije $s$ maksimalnim godišnjim uštedama za različite slučajeve stanja pojnog toka. Ghorbani $i$ sur. ${ }^{10}$ predstavili su metodologiju za optimizaciju sekvencija destilacijskih kolona koje su maksimalno toplinski integrirane, s ciljem pronalaska najbolje sekvencije separacije s minimalnim godišnjim troškovima. Wakabayashi $i$ Hasebe ${ }^{11}$ predložili su metodologiju primjenom modificiranog dijagrama Ponchon-Savarit. Primjenom predložene metodologije moguće je odrediti parove destilacijskih stupnjeva sekcija rektifikacije i stripiranja koji se toplinski integriraju u 
vanjskim izmjenjivačima topline. Dobiveni podatci mogu se primjenjivati za rigorozne simulacije destilacijskih kolona. Slične integracijske strukture razmatrali su Andreas $i$ Wolfgang ${ }^{12}$ s ciljem sinteze održivih destilacijskih procesa. Predložena metodologija zasniva se na građenju superstrukture i miješanog cjelobrojnog programiranja, primjenjujući rigorozne termodinamičke modele, uz minimizaciju ukupnih godišnjih troškova. Shahandeh i sur. ${ }^{13}$ predložili su rigorozne modele za toplinski integriranu destilacijsku kolonu i destilacijsku kolonu s rekompresijom pare kao alternativu konvencionalnom dizajnu s funkcijom cilja koja minimizira ukupne godišnje troškove. Shahandeh $i$ sur. ${ }^{13}$ predložili su i strategiju za razmatranje svih mogućih opcija za integraciju energije i pronalazak optimalne strukture koja je termodinamički i ekonomski pogodnija od konvencionalne.

Yang $i$ sur. $^{6}$ predstavili su sustavnu metodologiju za simultanu optimizaciju i toplinsku integraciju procesa destilacije $\mathrm{s}$ procesom iz pozadine i pokazali da se $u$ procesu mogu postići znatne uštede ako se destilacijski sustav toplinski integrira s procesom iz pozadine.

$\mathrm{U}$ ovom radu prikazana je bilanca tvari i energije toplinski neintegrirane $\mathrm{i}$ integrirane destilacijske kolone. Toplinska integracija omogućena je upotrebom energije toplih izlaznih tokova vrha i dna destilacijske kolone za predgrijavanje pojnog toka destilacijske kolone. Matematički modeli razvijeni su i riješeni u dva različita softverska paketa; u programu Microsoft Excel s VBA (Visual Basic for Applications) i u GAMS-u (General Algebraic Modeling System). ${ }^{14}$ Predloženi modeli određuju vrijednosti procesnih varijabli s ciljem određivanja minimalne potrošnje pogonskih sredstava uz simultanu minimizaciju pseudo ukupnih troškova izraženih kroz broj stupnjeva i refluksni odnos. Na taj način predstavljena je skraćena metodologija optimalizacije destilacijskog sustava primijenjena na sustavu aceton-metanol.

Cilj ovog rada je prikaz razvoja simulacijskog /optimizacijskog matematičkog modela destilacijske kolone s toplinskom integracijom i bez nje, primjenom različitih softverskih paketa. Prikazana je usporedba rezultata toplinski integrirane destilacijske kolone s rezultatima neintegrirane destilacijske kolone. Uspoređivane su sljedeće varijable: toplinska dužnost isparivača, toplinska dužnost predgrijača, toplinska dužnost kondenzatora, potrošnja pogonskih sredstava i temperatura ulazne binarne smjese. Rezultati su pokazali da se ušteda energije može postići primjenom toplinske integracije. Predloženi modeli mogu se primijeniti za projektiranje ili preuređenje destilacijskih kolona za razdvajanje binarnih smjesa.

\section{Teorijski dio}

Potrebno je utvrditi potrošnju energenata za destilacijski sustav u kojem se razdvaja binarna smjesa aceton-metanol. Proces destilacije odvija se pri atmosferskom tlaku i stupnju separacije koji je određen udjelom lakše hlapljive komponente u destilatu 94,0 mas.\% i teže hlapljive komponente u proizvodu dna 97,0 mas.\%. Destilacijska kolona opremljena je pliticama, a izmjenjivači topline cijevnim snopom u plaštu. Sastav i stanje pojne smjese je:

- protok $4500 \mathrm{kgh}^{-1}$,

- udio lakše hlapljive komponente 30,0 mas. \% i

- temperatura $30{ }^{\circ} \mathrm{C}$

Od energenata na raspolaganju su zasićena vodena para tlaka 15,0 bar i rashladna voda iz kružnog sustava, 20/30 ${ }^{\circ} \mathrm{C}$. Na slici 1 prikazana je toplinski neintegrirana destilacijska kolona, dok je na slici 2 prikazana toplinski integrirana destilacijska kolona.

Temperature procesnih tokova destilacijskog sustava su i funkcija svojstava sustava koji se razdvaja, odnosno parametara ravnoteže u sustavu. Pojna smjesa koja prelazi granice destilacijskog sustava je nezasićena i u predgrijaču treba biti dovedena do temperature zasićenja. Temperatura zasićenja sustava, odnosno temperatura pojenja destilacijske kolone, u potpunosti je određena ravnotežom u sustavu za poznat udio lakše hlapljive komponente i tlak sustava.

\section{Matematički model}

Ukupna bilanca tvari sustava prikazana je jedn. (1):

$$
\dot{m}_{1}=\dot{m}_{6}+\dot{m}_{10}
$$

Bilanca tvari u odnosu na aceton prikazana je jedn. (2):

$$
\dot{m}_{1} \cdot x_{1}^{(1)}=\dot{m}_{6} \cdot x_{6}^{(1)}+\dot{m}_{10} \cdot y_{10}^{(1)}
$$

Bilanca tvari kondenzatora prikazana je jedn. (3):

$$
\dot{m}_{7}=\dot{m}_{8}+\dot{m}_{9}
$$

Refluksni odnos kolone prikazan je jedn. (4):

$$
R=\frac{\dot{m}_{9}}{\dot{m}_{8}}
$$

Toplinska bilanca kondenzatora prikazana je jedn. (5):

$$
\dot{m}_{7} \cdot \hat{H}_{7}-Q_{\mathrm{TR}}^{(\mathrm{KOND})}=\dot{m}_{8} \cdot \hat{H}_{8}+\dot{m}_{9} \cdot \hat{h}_{9}
$$




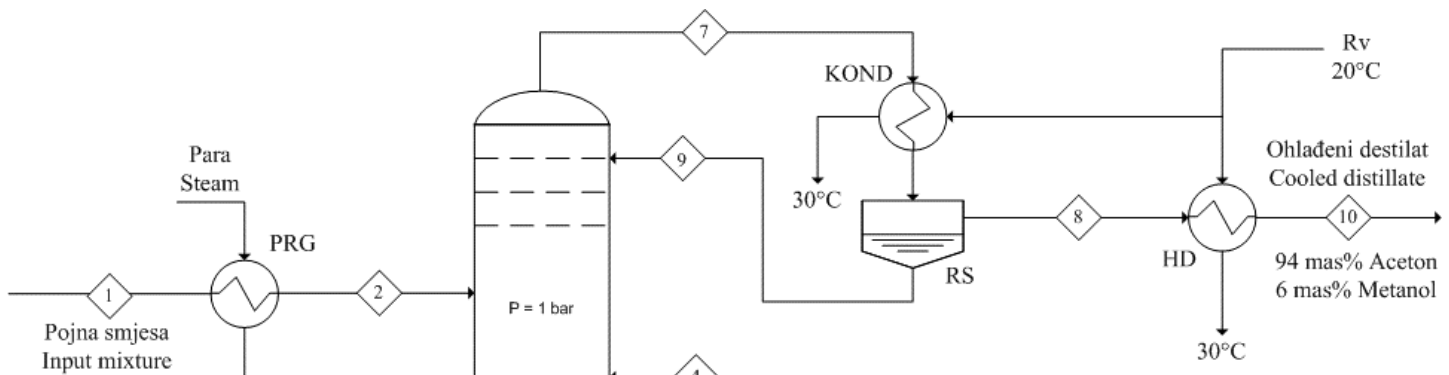
30 mas $\%$ Aceton $30^{\circ} \mathrm{C}$ Kondenzat Condensate

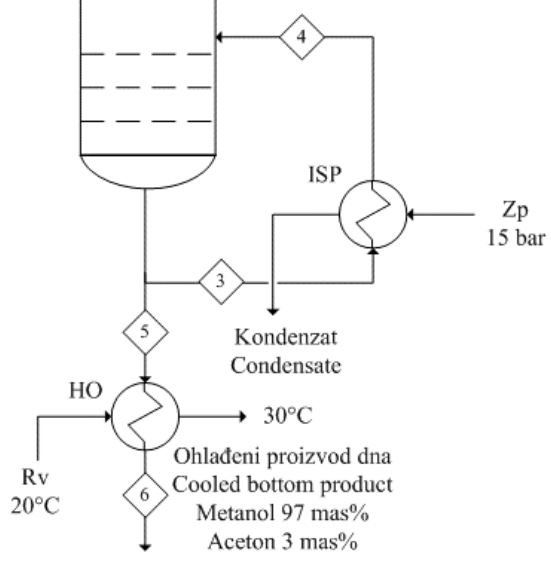

Legenda: Legend:

KOND - Kondenzator - Condenser ISP - Isparivač - Evaporator PRG - Predgrijač - Preheater HD - Hladnjak destilata - Distillate cooler

$\mathrm{HO}$ - Hladnjak proizvoda dna - Bottom cooler

Rv - Rashladna voda - Cooling water RS - Sabirnik refluksa - Reflux collector $\mathrm{ZP}$ - Zasićena para - Saturated steam

Slika 1 - Toplinski neintegrirana destilacijska kolona

Fig. 1 - Thermal non-integrated distillation column

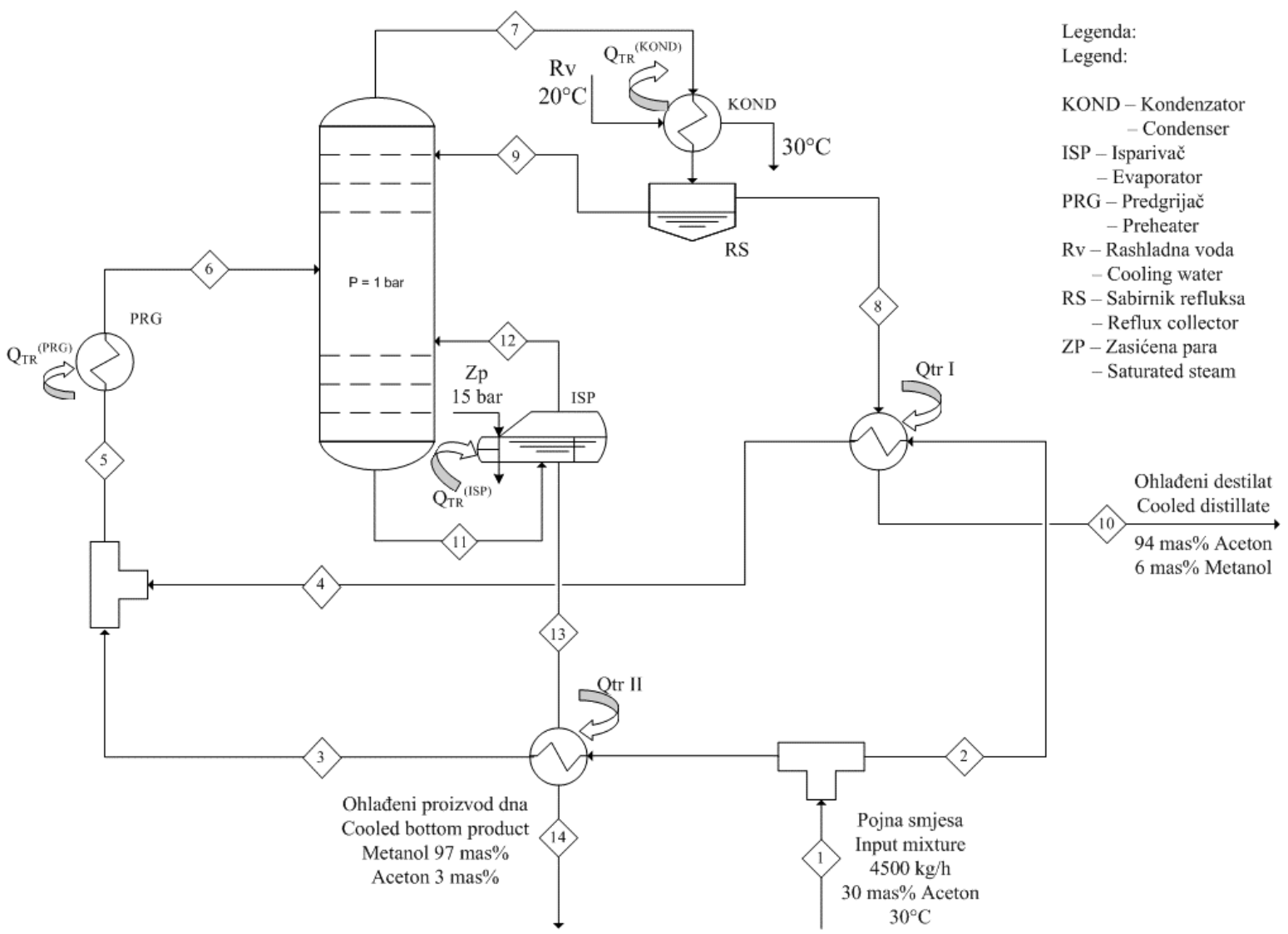

Slika 2 - Toplinski integrirana destilacijska kolona

Fig. 2 - Thermal integrated distillation column 
Specifična entalpija toka vrha kolone prikazana je jedn. (6):

$$
\hat{H}_{7}=y_{7}^{(1)} \cdot \hat{H}_{7}^{(1)}+\left(1-y_{7}^{(1)}\right) \cdot \hat{H}_{7}^{(2)}
$$

Specifična entalpija acetona u toku vrha kolone prikazana je jedn. (7):

$$
\hat{H}_{7}^{(1)}=\int_{T_{\text {ref }}}^{T_{\text {nvr, } 1}} C_{p, 1}(T) d T+\Delta \hat{H}_{v, 1}^{\left(T_{\text {nv, }}\right)}+\int_{T_{\text {nvv }, 1}}^{T_{\text {ros }}} C_{p, g}(T) d T
$$

Specifična entalpija metanola u toku vrha kolone prikazana je jedn. (8):

$$
\hat{H}_{7}^{(2)}=\int_{T_{\text {ref }}}^{T_{\text {nvr, }}} C_{p, 1}(T) d T+\Delta \hat{H}_{\mathrm{v}, 1}^{\left(T_{\text {nvr, }}\right)}+\int_{T_{\text {nv }, 2}}^{T_{\text {ros }}} C_{p, g}(T) d T
$$

Temperatura toka vrha kolone je temperatura rosišta na tlaku vrha kolone, a udio acetona u toku vrha kolone određen je ravnotežom u sustavu i prikazan je jedn. (9):

$$
T_{\text {ros }}=f\left(y_{7}^{(1)}, P_{\mathrm{uk}}\right)
$$

Specifična entalpija toka destilata prikazana je jedn. (10):

$$
\hat{h}_{8}=x_{8}^{(1)} \cdot \hat{h}_{8}^{(1)}+\left(1-x_{8}^{(1)}\right) \cdot \hat{h}_{8}^{(2)}
$$

Specifična entalpija acetona u toku destilata prikazana je jedn. (11).

$$
\hat{h}_{8}^{(1)}=\int_{T_{\text {ref }}}^{T_{8}} C_{p, l}(T) d T
$$

Specifična entalpija metanola u toku destilata prikazana je jedn. (12):

$$
\hat{h}_{8}^{(2)}=\int_{T_{\text {ref }}}^{T_{8}} C_{p, l}(T) d T
$$

Specifična entalpija toka refluksa prikazana je jedn. (13):

$$
\hat{h}_{9}=x_{9}^{(1)} \cdot \hat{h}_{9}^{(1)}+\left(1-x_{9}^{(1)}\right) \cdot \hat{h}_{9}^{(2)}
$$

Specifična entalpija acetona u toku refluksa prikazana je jedn. (14):

$$
\hat{h}_{9}^{(1)}=\int_{T_{\text {ref }}}^{T_{9}} C_{p, l}(T) d T
$$

Specifična entalpija metanola u toku refluksa prikazana je jedn. (15):

$$
\hat{h}_{9}^{(2)}=\int_{T_{\text {ref }}}^{T_{9}} C_{p, l}(T) d T
$$

Toplinska bilanca kondenzatora u odnosu na rashladni medij prikazana je jedn. (16):

$$
\bar{m}_{\mathrm{v}}=\frac{Q_{\mathrm{TR}}^{(\mathrm{KOND})}}{C_{p, \mathrm{v}} \cdot\left(t_{\mathrm{v}}^{(\mathrm{iz})}-t_{\mathrm{v}}^{(\mathrm{ul})}\right)}
$$

Toplinska bilanca predgrijača prikazana je jedn. (17):

$$
\dot{m}_{1} \cdot \hat{h}_{1}+Q_{\mathrm{TR}}^{(\mathrm{PRG})}=\dot{m}_{2} \cdot \hat{h}_{2}
$$

Specifična entalpija toka koji napušta predgrijač prikazana je jedn. (18):

$$
\hat{h}_{2}=x_{2}^{(1)} \cdot \hat{h}_{2}^{(1)}+\left(1-x_{2}^{(1)}\right) \cdot \hat{h}_{2}^{(2)}
$$

Specifična entalpija acetona u toku koji napušta predgrijač prikazana je jedn. (19):

$$
\hat{h}_{2}^{(1)}=\int_{T_{\text {ref }}}^{T_{2}} C_{p, l}(T) d T
$$

Specifična entalpija metanola u toku koji napušta predgrijač prikazana je jedn. (20):

$$
\hat{h}_{2}^{(2)}=\int_{T_{\text {ref }}}^{T_{2}} c_{p, l}(T) d T
$$

Temperatura pojnog toka destilacijske kolone je temperatura vrelišta na tlaku na ulazu u kolonu i udio acetona u pojnom toku destilacijske kolone određen je ravnotežom u sustavu i prikazan je jedn. (21):

$$
T_{2}=f\left(x_{2}^{(1)}, P_{\mathrm{uk}}\right)
$$

Bilanca topline destilacijske kolone prikazana je jedn. (22):

$$
\dot{m}_{1} \cdot \hat{h}_{1}+Q_{\mathrm{TR}}^{(\mathrm{PRG})}-Q_{\mathrm{TR}}^{(\mathrm{KOND})}+Q_{\mathrm{TR}}^{(\mathrm{ISP})}=\dot{m}_{5} \cdot \hat{h}_{5}+\dot{m}_{8} \cdot \hat{H}_{8}
$$

Za proračun se pretpostavljaju referentni uvjeti $t_{\text {ref }}=t_{1}$ (temperatura pojne smjese) i tekuće fazno stanje, pa proizlazi da je entalpija $\hat{h}_{1}=0$.

Specifična entalpija toka proizvoda dna kolone prikazana je jedn. (23):

$$
\hat{h}_{5}=x_{5}^{(1)} \cdot \hat{h}_{5}^{(1)}+\left(1-x_{5}^{(1)}\right) \cdot \hat{h}_{5}^{(2)}
$$

Specifična entalpija acetona u toku refluksa prikazana je jedn. (24):

$$
\hat{h}_{5}^{(1)}=\int_{T_{\text {ref }}}^{T_{5}} C_{p, 1}(T) d T
$$


Specifična entalpija metanola u toku refluksa prikazana je jedn. (25):

$$
\hat{h}_{5}^{(2)}=\int_{T_{\text {ref }}}^{T_{5}} C_{p, 1}(T) d T
$$

Toplinska bilanca isparivača $u$ odnosu na ogrjevni medij prikazana je jedn. (26):

$$
\bar{m}_{\mathrm{p}}=\frac{Q_{\mathrm{TR}}^{(\mathrm{ISP})}}{\Delta \hat{H}_{\mathrm{v}}}
$$

Toplinska bilanca hladnjaka destilata u odnosu na rashladni medij prikazana je jedn. (27):

$$
\bar{m}_{\mathrm{v}}^{(\mathrm{HD})}=\frac{Q_{\mathrm{TR}}^{(\mathrm{HD})}}{C_{p, \mathrm{v}} \cdot\left(t_{\mathrm{v}}^{(\mathrm{z})}-t_{\mathrm{v}}^{(\mathrm{Ul})}\right)}
$$

Toplinska bilanca hladnjaka destilata u odnosu na tok kojim se grije prikazana je jedn. (28):

$$
Q_{\mathrm{TR}}^{(\mathrm{HD})}=\dot{m}_{8} \cdot\left(\hat{H}_{8}-\hat{H}_{10}\right)
$$

Specifična entalpija toka destilata na izlazu iz hladnjaka proizvoda dna kolone prikazana je jedn. (29):

$$
\hat{h}_{10}=\int_{T_{\text {ref }}}^{T_{10}} c_{p, s m}(T) d T
$$

Toplinska bilanca izmjenjivača (I) u odnosu na tok koji se grije prikazana je jedn. (30):

$$
Q_{\mathrm{TR}}^{(l)}=\dot{m}_{2} \cdot\left(\hat{h}_{4}-\hat{h}_{2}\right)
$$

Specifična entalpija toka koji se grije na izlazu iz izmjenjivača (I) prikazana je jedn. (31):

$$
\hat{h}_{4}=f\left(T_{4}\right)
$$

Toplinska bilanca hladnjaka proizvoda dna u odnosu na rashladni medij prikazana je jedn. (32):

$$
\bar{m}_{\mathrm{v}}^{(\mathrm{HO})}=\frac{Q_{\mathrm{TR}}^{(\mathrm{HO})}}{C_{p, \mathrm{v}} \cdot\left(t_{\mathrm{v}}^{(\mathrm{iz})}-t_{\mathrm{v}}^{(\mathrm{ul})}\right)}
$$

Toplinska bilanca hladnjaka proizvoda dna u odnosu na tok koji se grije prikazana je jedn. (33):

$$
Q_{\mathrm{TR}}^{(\mathrm{HO})}=\dot{m}_{5} \cdot\left(\hat{h}_{5}-\hat{h}_{6}\right)
$$

Specifična entalpija toka destilata na izlazu iz hladnjaka ostatka prikazana je jedn. (34):

$$
\hat{h}_{6}=\int_{T_{\text {ef }}}^{T_{6}} c_{p, s m}(T) d T
$$

Toplinska bilanca izmjenjivača (II) u odnosu na tok koji se grije prikazana je jedn. (35):

$$
Q_{\mathrm{TR}}^{(\mathrm{II})}=\dot{m}_{3} \cdot\left(\hat{h}_{3}-\hat{h}_{1}\right)
$$

Specifična entalpija toka koji se grije na izlazu iz izmjenjivača (II) prikazana je jedn. (36):

$$
\hat{h}_{3}=f\left(T_{3}\right)
$$

Pojni tok dijeli se na tokove 2 i 3 preko odnosa prenesene količine topline u izmjenjivačima I i II (jedn. (37)):

$$
\frac{Q_{\mathrm{TR}}^{(1)}}{Q_{\mathrm{TR}}^{(1)}}=\frac{\dot{m}_{2}}{\dot{m}_{3}}
$$

Bilanca tvari odvajača (slika 2) prikazana je jedn. (38):

$$
\dot{m}_{1}=\dot{m}_{2}+\dot{m}_{3}
$$

Toplinska bilanca mješača (slika 2) prikazana je jedn. (39):

$$
\dot{m}_{2} \cdot \hat{h}_{4}+\dot{m}_{3} \cdot \hat{h}_{3}=\dot{m}_{5} \cdot \hat{h}_{5}
$$

Specifična entalpija toka na izlazu iz odvajača (slika 2) prikazana je jedn. (40):

$$
\hat{h}_{5}=f\left(T_{5}\right)
$$

Minimalan broj ravnotežnih stupnjeva može se izračunati iz jednadžbe Fenskea ${ }^{3}$ (jedn. (41)):

$$
N_{\text {min }}=\frac{1}{\log \alpha} \cdot \log \left(\frac{x_{D} \cdot\left(1-x_{B}\right)}{x_{B} \cdot\left(1-x_{D}\right)}\right)
$$

Relativna hlapljivost acetona na temperaturi vrha i dna kolone računa se iz jedn. (42) i (43):

$$
\begin{gathered}
\alpha_{\mathrm{vrh}}=\frac{\mathrm{e}^{\left(A_{1}-B_{1} /\left(T_{\mathrm{vh}}+C_{1}\right)\right)}}{\mathrm{e}^{\left(A_{2}-B_{2} /\left(T_{\mathrm{vh}}+C_{2}\right)\right)}} \\
\alpha_{\mathrm{dno}}=\frac{e^{\left(A_{1}-B_{1} /\left(T_{\mathrm{dno}}+C_{1}\right)\right)}}{\mathrm{e}^{\left(A_{2}-B_{2} /\left(T_{\mathrm{dno}}+C_{2}\right)\right)}}
\end{gathered}
$$

Relativna hlapljivost acetona u odnosu na metanol na srednjoj temperaturi računa se iz jedn. (44):

$$
\alpha=\sqrt{\alpha_{\mathrm{vrh}} \cdot \alpha_{\mathrm{dno}}}
$$

Vrijednost minimalnog refluksa može se računati iz jedn. (45), za uvjete vrelišta na ulazu u kolonu: ${ }^{3}$

$$
R_{\text {min }}=\frac{1}{\alpha-1} \cdot\left(\frac{x_{\mathrm{D}}}{x_{\mathrm{F}}}-\alpha \cdot \frac{\left(1-x_{\mathrm{D}}\right)}{\left(1-x_{\mathrm{F}}\right)}\right)
$$

Vrijednost stvarnog refluksnog odnosa računa se iz jedn. (46): 


$$
R=\beta \cdot R_{\min }
$$

Broj idealnih stupnjeva računa se postupkom Gillilanda, na osnovu jedn. (47) i (48): ${ }^{3}$

$$
\begin{aligned}
& Y=\frac{N-N_{\text {min }}}{N+1} \\
& X=\frac{R-R_{\text {min }}}{R+1}
\end{aligned}
$$

Vrijednost $Y$ računa se iz jedn. (49): ${ }^{3}$

$$
Y=1.0-\exp \left[\left(\frac{1+54.4 \cdot X}{11.0+117.2 \cdot X}\right) \cdot\left(\frac{X-1}{X^{0.5}}\right)\right]
$$

\section{Rezultati i rasprava}

U tablici 1 prikazani su rezultati analitičke metode za određivanje broja ravnotežnih stupnjeva.

Tablica 1 - Rezultati grafičke metode za određivanje broja ravnotežnih stupnjeva

Table 1 - Results of the graphic method for determining the number of equilibrium stages

\begin{tabular}{c|c|c|c|c|c}
\hline$\beta$ & $R$ & $X$ & $Y$ & $N$ & $N \cdot(R+1)$ \\
\hline 1,20 & 15,55 & 0,16 & 0,49 & 41,62 & 688,87 \\
1,30 & 16,85 & 0,22 & 0,44 & 37,56 & 670,34 \\
1,40 & 18,14 & 0,27 & 0,40 & 34,92 & 668,61 \\
1,50 & 19,44 & 0,32 & 0,37 & 33,05 & 675,59 \\
1,60 & 20,74 & 0,36 & 0,34 & 31,64 & 687,75 \\
1,70 & 22,03 & 0,39 & 0,31 & 30,53 & 703,26 \\
1,80 & 23,33 & 0,43 & 0,29 & 29,64 & 721,09 \\
1,90 & 24,62 & 0,45 & 0,27 & 28,90 & 740,58 \\
2,00 & 25,92 & 0,48 & 0,26 & 28,28 & 761,32 \\
2,10 & 27,22 & 0,51 & 0,25 & 27,75 & 783,01 \\
2,20 & 28,51 & 0,53 & 0,23 & 27,29 & 805,45 \\
2,30 & 29,81 & 0,55 & 0,22 & 26,89 & 828,49 \\
2,40 & 31,11 & 0,56 & 0,21 & 26,54 & 852,02 \\
2,50 & 32,40 & 0,58 & 0,20 & 26,22 & 875,95 \\
2,60 & 33,69 & 0,59 & 0,19 & 25,94 & 900,22 \\
\hline
\end{tabular}

Na slici 3, koja predstavlja $N \cdot(R+1)=\mathrm{f}(R)$, stvarni refluksni odnos za dani interval $\beta$ ima vrijednost 17,67 , što odgovara 35,81 ravnotežnih stupnjeva pri radnom omjeru refluksa 1,36. Funkcija cilja predstavlja jednu od skraćenih metodologija optimizacije za simultanu minimizaciju pseudo ukupnih troškova izraženih brojem stupnjeva i refluksnim odnosom.

Usporedba rezultata za destilacijsku kolonu s toplinskom integracijom i bez toplinske integracije prikazani su u tablici 2.

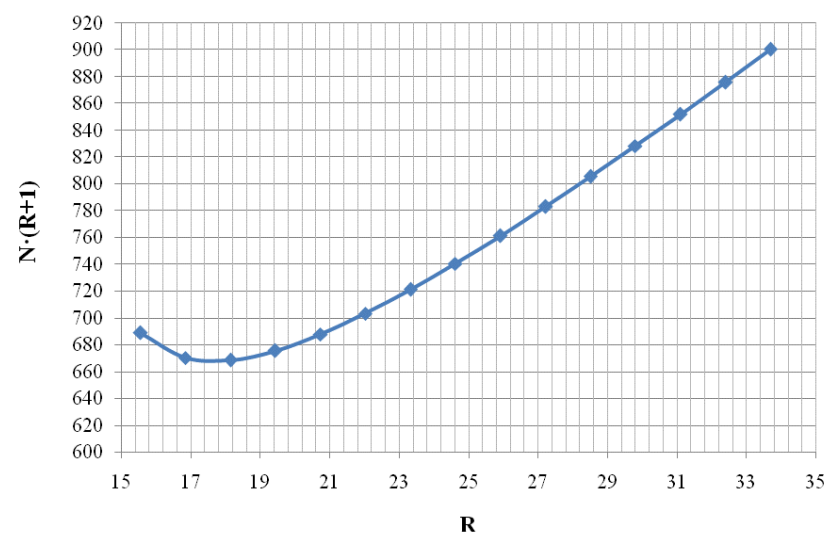

Slika 3 - Grafičko određivanje idealnog broja stupnjeva

Fig. 3 - Graphical determination of the ideal number of degrees

Tablica 2 - Usporedba rezultata za destilacijsku kolonu s toplinskom integracijom i bez toplinske integracije

Table 2 - Comparison of the results for the distillation column with and without heat integration

\begin{tabular}{|c|c|c}
\hline & $\begin{array}{c}\text { S toplinskom } \\
\text { integracijom } \\
\text { With heat } \\
\text { integration }\end{array}$ & $\begin{array}{c}\text { Bez toplinske } \\
\text { integracije } \\
\text { Without heat } \\
\text { integration }\end{array}$ \\
\hline
\end{tabular}

Toplinski tok

kondenzatora, $\mathrm{kj} \mathrm{h}^{-1}$

Heat flow of the

$13.407 .002,12 \quad 13.407 .002,12$

condenser, $\mathrm{kj} \mathrm{h}^{-1}$

Potrošnja rashladne vode $u$

kondenzatoru, $\mathrm{kg} \mathrm{h}^{-1}$

Consumption of cooling water

$320.281,94 \quad 320.281,94$

in the condenser, $\mathrm{kg} \mathrm{h}^{-1}$

Toplinski tok isparivača, $\mathrm{kj} \mathrm{h}^{-1}$

Heat flow of evaporator, $\mathrm{kj} \mathrm{h}^{-1}$

Potrošnja pare, $\mathrm{kg} \mathrm{h}^{-1}$

Consumption of steam, $\mathrm{kgh}^{-1}$

$6.882,95$

Toplinski tok predgrijača, $\mathrm{kj} \mathrm{h}^{-1}$

Heat flow of preheater, $\mathrm{kj} \mathrm{h}^{-1}$

$116.015,80 \quad 374.144,69$

Temperatura na ulazu u

predgrijač, ${ }^{\circ} \mathrm{C}$

53,03

30,00

Preheater inlet temperature, ${ }^{\circ} \mathrm{C}$

Potrošnja rashladne vode za

hlađenje toka destilata, $\mathrm{kg} \mathrm{h}^{-1}$

Consumption of cooling water

for cooling the distillate

stream, $\mathrm{kgh}^{-1}$

Potrošnja rashladne vode za

hlađenje toka proizvoda

dna, $\mathrm{kg} \mathrm{h}^{-1}$

Consumption of cooling water

for cooling the product flow of

the bottom, $\mathrm{kg} \mathrm{h}^{-1}$

$4.933,14$
Iz tablice 2 uočljivo je da se toplinski tokovi kondenzatora i isparivača ne mijenjaju jer ne dolazi do promjene 
temperature vrha kolone niti do promjene temperature dna kolone, koje su u izravnoj vezi s udjelom lakše hlapljive komponente. Također još jedan od razloga zašto se navedeni toplinski tokovi ne mijenjaju je taj što nisu uzeti u obzir pri integraciji. U slučaju destilacijske kolone s toplinskom integracijom izbjegla bi se potrošnja rashladne vode za hlađenje toka destilata 1233,34 $\mathrm{kg} \mathrm{h}^{-1}$ i proizvoda dna kolone $4933,14 \mathrm{kgh}^{-1}$, što je s aspekta troškova pogonskih sredstava od iznimne važnosti. $U$ ovom radu toplinska dužnost isparivača iznosi $3722,62 \mathrm{~kW}$, dok toplinska dužnost kondenzatora iznosi $3724,17 \mathrm{~kW}$. Također možemo vidjeti da u slučaju destilacijske kolone s toplinskom integracijom, temperatura pojne smjese dostiže vrijednost $53,03^{\circ} \mathrm{C}$ na ulazu u predgrijač, što znatno smanjuje troškove svježe pare za dovođenje smjese do stanja vrelišta na ulazu u destilacijsku kolonu. U budućim istraživanjima trebalo bi se fokusirati na dimenzioniranje kolone, kao i ostale procesne opreme sa sheme - grijača, isparivača te kondenzatora. Također, fokus bi bio i na ekonomskoj analizi za slučaj s optimizacijom i bez optimizacije, odnosno uključiti cijene rashladne vode za hlađenje i pare za grijanje sustava. U tom slučaju vidjela bi se stvarna razlika između integrirane i neintegrirane destilacijske kolone, troškovi investicija i pogonskih sredstava.

\section{Zaključak}

Primjenom toplinske integracije smanjuje se količina topline koja se dovodi s parom za predgrijavanje pojenja prije uvođenja u destilacijsku kolonu, što utječe na smanjenje troškova razdvajanja binarne smjese kao i smanjenje potrošnje rashladne vode kao pogonskog sredstva za hlađenje toka destilata i proizvoda dna kolone. Kreirani procesni simulatori mogu se primijeniti za simulaciju razdvajanja bilo kojeg binarnog sustava, ali zahtijevaju unošenje fizikalno-kemijskih osobina odgovarajućeg binarnog sustava. Kreirani procesni simulatori ne mogu se primijeniti za simulaciju razdvajanja trokomponentnih sustava.

\section{Popis kratica i simbola}

\section{List of abbreviations and symbols}

$$
\begin{array}{cl}
A_{1} & \text { - parametar za aceton u Antoineovoj jednadžbi, - } \\
& \text { - parameter for acetone in Antoine equation, }- \\
A_{2} & \text { - parametar za metanol u Antoineovoj jednadžbi, } \\
& \text { - parameter for methanol in Antoine equation, }- \\
B_{1} & \text { - parametar za aceton u Antoineovoj jednadžbi, } \\
& \text { - parameter for acetone in Antoine equation, - } \\
B_{2} & \text { - parametar za metanol u Antoineovoj jednadžbi, - } \\
& \text { - parameter for methanol in Antoine equation, }-
\end{array}
$$

$C_{1} \quad$ - parametar za aceton u Antoineovoj jednadžbi, -

- parameter for acetone in Antoine equation, -

$C_{2} \quad$ - parametar za metanol u Antoineovoj jednadžbi, -

- parameter for methanol in Antoine equation, -

- specifični toplinski kapacitet vode pri konstantnom pritisku, $\mathrm{kJ} \mathrm{kg}^{-1} \mathrm{~K}^{-1}$

$c_{p, v} \quad$ - specific heat capacity of water at constant pressure, $\mathrm{kJ} \mathrm{kg}^{-1} \mathrm{~K}^{-1}$

- specifični toplinski kapacitet smjese pri konstantnom pritisku, $\mathrm{kJ} \mathrm{kmol}^{-1} \mathrm{~K}^{-1}$

$c_{p, s m}-$ specific heat capacity of mixture at constant pressure, $\mathrm{kJ} \mathrm{kmol}^{-1} \mathrm{~K}^{-1}$

- specifični toplinski kapacitet tečnog toka pri konstantnom pritisku, $\mathrm{kJ} \mathrm{kmol}^{-1} \mathrm{~K}^{-1}$

$c_{p, 1} \quad$ - specific heat capacity of liquid stream at constant pressure, $\mathrm{kJ} \mathrm{kmol}^{-1} \mathrm{~K}^{-1}$

- specifični toplinski kapacitet parovitog toka pri konstantnom pritisku, $\mathrm{kJ} \mathrm{kmol}^{-1} \mathrm{~K}^{-1}$

$c_{p, g} \quad$ - specific heat capacity of vapour stream at constant pressure, $\mathrm{kJ} \mathrm{kmol}^{-1} \mathrm{~K}^{-1}$

$\hat{h}_{\mathrm{i}} \quad$ - specifična entalpija tečnog toka, $\mathrm{kJ} \mathrm{kmol}^{-1}$

$\hat{h}_{\mathrm{i}} \quad$ - specific enthalpy of liquid stream, $\mathrm{kJ} \mathrm{kmol}^{-1}$

- specifična entalpija komponente (j)

$\begin{array}{ll}\hat{h}_{\mathrm{i}}^{(\mathrm{j})} & \mathrm{u} \text { tečnom toku (i), } \mathrm{kJ} \mathrm{kmol}^{-1} \\ - \text { specific enthalpy of component (j) }\end{array}$ in liquid stream (i) , $\mathrm{kJ} \mathrm{kmol}^{-1}$

$\hat{H}_{\mathrm{i}} \quad$ - specifična entalpija parovitog toka, $\mathrm{kJ} \mathrm{kmol}^{-1}$

- specific enthalpy of vapour stream, $\mathrm{kJ} \mathrm{kmol}^{-1}$

- specifična entalpija komponente (j)

$\hat{H}_{\mathrm{i}}^{(\mathrm{j})} \quad$ u parovitom toku (i), $\mathrm{kJ} \mathrm{kmol}^{-1}$

- specific enthalpy of component (j) in vapour stream (i), $\mathrm{kJ} \mathrm{kmol}^{-1}$

$\dot{m}_{\mathrm{i}} \quad-$ molarni protok toka, $\mathrm{kmolh}^{-1}$

- molar flow rate, $\mathrm{kmol} \mathrm{h}^{-1}$

$\bar{m}_{v} \quad$ - protok rashladne vode, $\mathrm{kgh}^{-1}$

$\bar{m}_{v} \quad$-flow of cooling water, $\mathrm{kg} \mathrm{h}^{-1}$

$\bar{m}_{\mathrm{p}} \quad$ - protok ogrijevne pare, $\mathrm{kg} \mathrm{h}^{-1}$

-flow of heating steam, $\mathrm{kg} \mathrm{h}^{-1}$

- potrošnja rashladne vode za

$\bar{m}_{v}^{(\mathrm{HD})} \quad$ hlađenje toka destilata, $\mathrm{kg} \mathrm{h}^{-1}$

- consumption of cooling water for cooling the distillate stream, $\mathrm{kg} \mathrm{h}^{-1}$

- potrošnja rashladne vode za

$\bar{m}_{\mathrm{v}}^{(\mathrm{HO})} \quad$ hlađenje toka proizvoda dna, $\mathrm{kg} \mathrm{h}^{-1}$

- consumption of cooling water for cooling the product flow of the bottom, $\mathrm{kg} \mathrm{h}^{-1}$

$N$

- stvarni broj stupnjeva, -

- real number of stages, -

- minimalan broj stupnjeva, -

$N_{\text {min }} \quad-$ minimum number of stages, -

- ukupni pritisak, bar

- total pressure, bar 


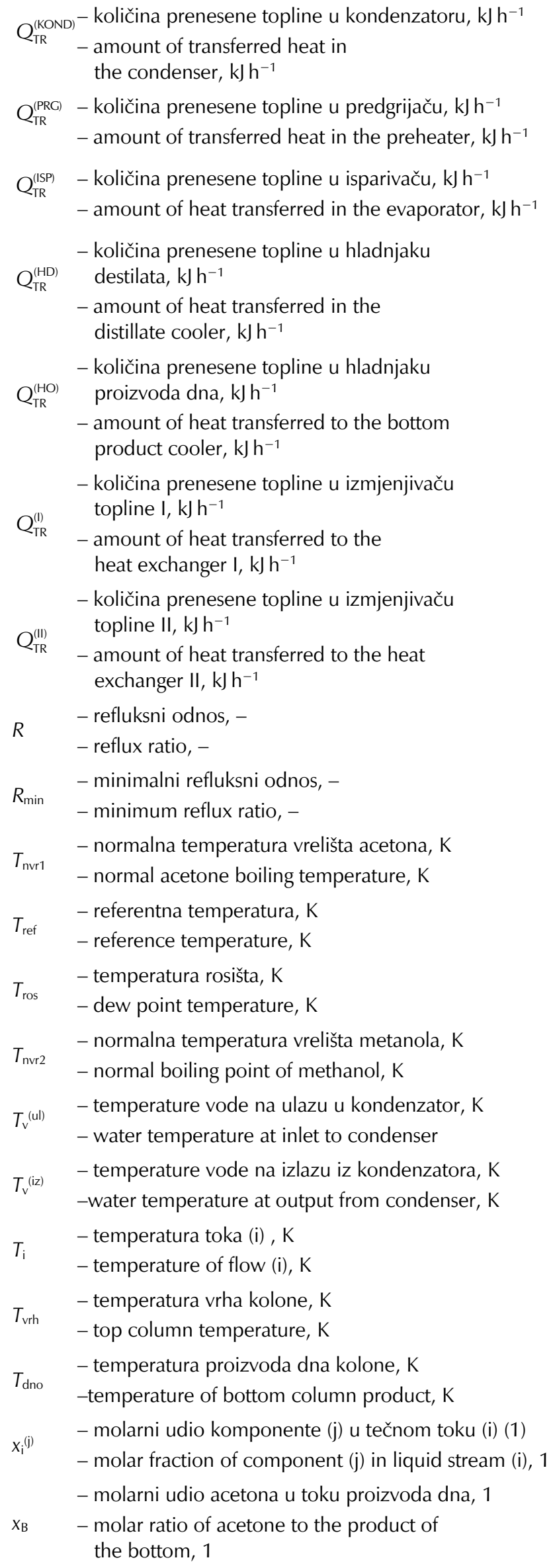

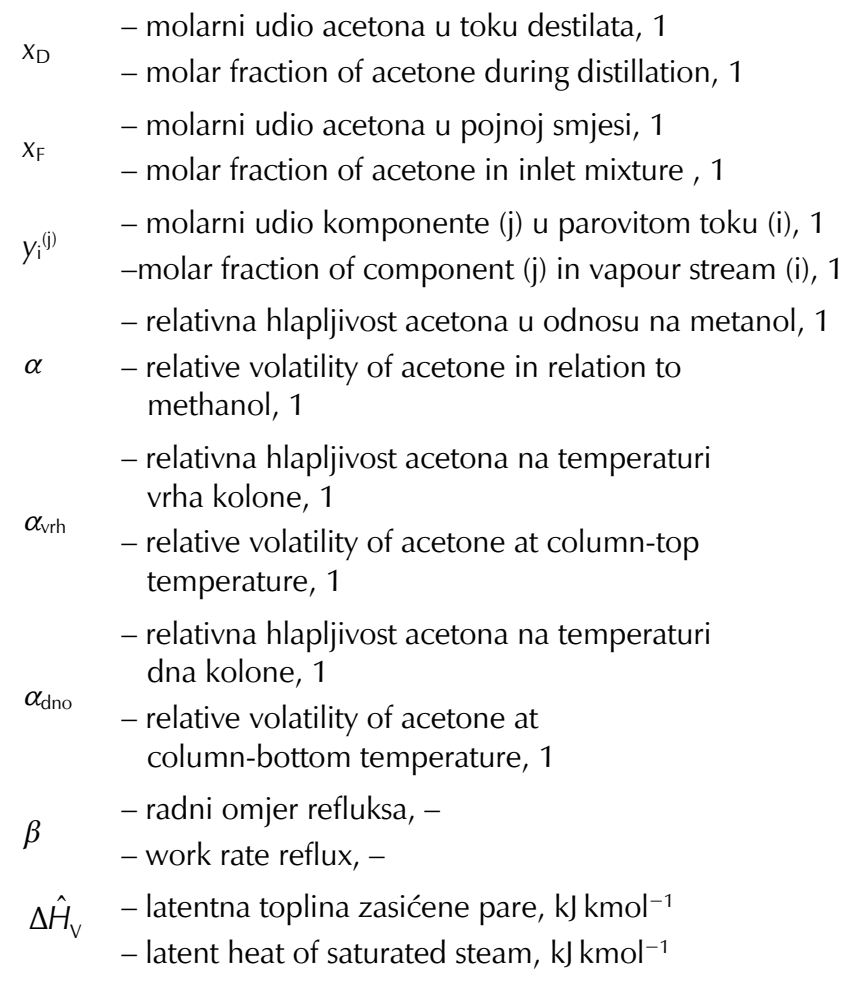

\section{Literatura}

References

1. B. Kotai, P. Lang, G. Modla, Batch extractive distillation as a hybrid process: separation of minimum boiling azeotropes, Chem. Eng. Sci. 62 (23) (2007) 6816-6826, doi: https://doi.org/10.1016/j.ces.2006.10.002.

2. A. A. Kiss, Ž. Olujić, A review on process intensification in internally heat-integrated distillation columns, Chem. Eng. Proc. Proc. Intens. 86 (2014) 125-144, doi: https://doi.org/10.1016/j.cep.2014.10.017.

3. C. Cui, X. Li, H. Sui, J. Sun, Quick Decision-Making for CloseBoiling Distillation Schemes, Ind. Eng. Chem. Res. 56 (2017) 5078-5091, doi: https://doi.org/10.1021/acs.iecr.7b00935.

4. J. J. Klemeš, Z. Kravanja, Forty years of Heat Integration: Pinch Analysis (PA) and Mathematical Programming (MP), Curr. Opin. Chem. Eng. 2 (4) (2013) 461-474, doi: https://doi.org/10.1016/j.coche.2013.10.003.

5. S. Jain, R. Smith, J. K. Kim, Synthesis of heat-integrated distillation sequence systems, J. Taiwan Institute Chem. Eng. 43 (4) (2012) 525-534, doi: https://doi.org/10.1016/j.jtice.2012.01.012.

6. M. Yang, X. Feng, G. Liu, Heat integration of heat pump assisted distillation into the overall process, Appl. Energy 162 (2016) 1-10, doi: https://doi.org/10.1016/j.apenergy.2015.10.044.

7. J. P. Schmal, H. J. Van Der Kooi, A. De Rijke, Ž. Olujić, P. J. Jansens, Internal Versus External Heat Integration: Operational and Economic Analysis, Chem. Eng. Res. Des. 84 (5) (2006) 374-380, doi: https://doi.org/10.1205/cherd05041.

8. A. K. Jana, Heat integrated distillation operation, Appl. Energy 87 (5) (2010) 1477-1494, doi: https://doi.org/10.1016/j.apenergy.2009.10.014. 
9. URL:https://scholar.google.hr/scholar?hl=hr\&as_sdt=0\%2C5 $\& q=$ Optimization + of + Conventional $+\% 3$ Fand + Energyinteg rated+Distillation + Configurations + at + Different + Feed + Co nditions+Mansour+\%3FKhalifa+and+Mansour+Emtir\&btn G (24. 6. 2018.).

10. B. Ghorbani, G. R. Salehi, P. Esnaashary, M. Amidpour, Design and Optimization of Heat Integrated Distillation, Energy Sci. Technol. 3 (2) (2012) 29-37, doi: https://doi.org/10.3968/j.est.1923847920120302.324.

11. T. Wakabayashi, S. Hasebe, Design of heat integrated distillation column by using $\mathrm{H}-x y$ and $\mathrm{T}-x y$ diagrams, Comp. Chem. Eng. 56 (2013) 174-183,

doi: https://doi.org/10.1016/j.compchemeng.2013.05.020.
12. H. Andreas, M. Wolfgang, Heat-integrated distillation columns: Vapor recompression or internal heat integration, AIChE J. 58 (12) (2012) 3740-3750, doi: https://doi.org/10.1002/aic.13775.

13. H. Shahandeh, J. Ivakpour, N. Kasiri, Feasibility study of heatintegrated distillation columns using rigorous optimization, Energy 74 (2014) 662-674, doi: https://doi.org/10.1016/j.energy.2014.07.032.

14. R. E. Rosenthal, GAMS: A User's Guide: GAMS Development Corporation, Washington, DC, 2015., USA, URL: https://www.gams.com/ (24. 6. 2018.).

\section{SUMMARY \\ Minimization of Utilities Consumption in a Distillation Column with and without Heat Integration for Separation of a Binary System of Acetone-Methanol \\ Nesib Mustafić* and Ervin Karić}

In this work, mathematical models for a distillation column with and without heat integration have been developed. Simulation based on the developed mathematical models was used to determine the energy consumption in the distillation column for separation of a binary system of acetone and methanol. The proposed models determine the values of process variables in order to obtain the minimum utilities consumption. The comparison of results of the heat-integrated distillation column with those of the non-integrated distillation column are presented. The results show that energy savings could be achieved using heat integration. The proposed models may be applied to the design of new or redesign of existing distillation columns for separation of binary mixtures.

\section{Keywords}

Binary system, distillation column, heat integration, utilities, simulation of the distillation process

Department of Chemical Engineering

Received April 9, 2018

Faculty of Technology, University of Tuzla

Accepted July 5, 2018

75000 Tuzla

Bosnia and Herzegovina 
